\title{
Point of care ultrasound - a way to reduce radiation exposure of patients and medical staff
}

\author{
T Zawada*, A Wieczorek, P Garba \\ From ESICM LIVES 2015 \\ Berlin, Germany. 3-7 October 2015
}

\section{Introduction}

Lungs ultrasonography and echocardiography is used by intensivist to provide assessments in patients with significant respiratory and cardiac diseases.

Transthoracic lung ultrasound allows to detect lung aerations and consolidations, to find pneumothorax or hydrothorax, localize alveolar-interstitial edema. It is also used as a monitoring tool to detect reaeration resulting from efficient treatment of pneumonia and lung recruitment resulting from PEEP. All the ultrasonographic measurements are made noninvasively and at the patient's bedside. Lung ultrasonography has been performed in our ICU for three years. Since then a tendency to reduce number of chest $\mathrm{x}$-rays and chest $\mathrm{CT}$ has been observed.

\section{Objectives}

The aim of the study was to analyze whether usage of the lung utlrasonography as a diagnostic and monitoring tool leads to minimize the number of chest $\mathrm{x}$-rays and chest $\mathrm{CT}$ and radiation dose in the ICU.

\section{Methods}

Data from 2 years before and 2 years after implementing a routine lung ultrasonography have been compared and statistical analysis has been made.

\section{Results}

\section{Conclusions}

The ability to perform transthoracic lung ultrasonography allowed us to reduce number of chest $x$-rays, chest$\mathrm{CT}$ and overall radiation dose. The implementation of new diagnostic technique did not influence on length of hospital stay or mortality.
Table 1

\begin{tabular}{llll}
\hline & $\mathbf{2 0 1 1 - 2 0 1 2}$ & $\mathbf{2 0 1 3 - 2 0 1 4}$ & $\mathbf{p}$ \\
\hline Number of hospitalized patients & 666 & 648 & NS \\
\hline SAPS2 & 52,6 & 53,0 & NS \\
\hline $\begin{array}{l}\text { Mean time of ICU hospitalization } \\
\text { (days) }\end{array}$ & 7,1 & 8,0 & NS \\
\hline Number of chest x-rays & 1744 & 1612 & NS \\
\hline NUMBER OF CHEST-CT & 52 & 34 & $\mathrm{p}<0,05$ \\
\hline $\begin{array}{l}\text { SUMMARISE DOSE OF RADIATION/ } \\
\text { YEAR [mGY/1,70 m2 BSA] }\end{array}$ & 1199,2 & 925,6 & $\mathrm{p}<0,05$ \\
\hline $\begin{array}{l}\text { Mean time of mechanical } \\
\text { ventilation }\end{array}$ & 6,2 & 8,3 & NS \\
\hline Mortality & $36,5 \%$ & $36,0 \%$ & NS \\
\hline
\end{tabular}

\section{Grant Acknowledgment} ICU Staff.

Published: 1 October 2015

References

1. Bouhemad B, et al: Ultrasound assessment of antibiotic-induced pulmonary reaeration in ventilator-associated pneumonia. Crit Care Med 2010, 38(1):84-92, Jan.

2. Soummer A: Ultrasound assessment of lung aeration loss during a successful weaning trial predicts postextubation distress. Crit Care Med 2012, 40(7):2064-72, Jul.

3. Algieri I, et al: CT scan and ultrasound comparative assessment of PEEPinduced lung aeration changes in ARDS. Crit Care Med 2014, 18(Suppl 1): P285.

4. Bouhemad B., et al: Bedside ultrasound assessment of positive endexpiratory pressure-induced lung recruitment. Am J Respir Crit Care Med 2011, 183:341-347.

5. Gargani L: Lung ultrasound a new tool for the cardiologist. Cardiovasc Ultrasound 2011, 9:6.

doi:10.1186/2197-425X-3-S1-A273

Cite this article as: Zawada et al:: Point of care ultrasound - a way to reduce radiation exposure of patients and medical staff. Intensive Care Medicine Experimental 2015 3(Suppl 1):A273. 